DOI: $10.12731 / 2306-1561-2013-4-10$

\title{
STUDY INFORMATION SYSTEMS SUPPLIER RELATIONSHIP MANAGEMENT
}

\author{
Sinha Babu Raja, Ostroukh A.V.
}

\section{Abstract}

This article analyzes the various approaches to building information systems that automate the processes of accounting, planning and control. It is shown that the system of supply chain management provides a single information space for all the companies involved in the manufacture of the product, its distribution, sales and after-sales service.

Keywords: information systems, customer relationship management (CRM), enterprise resource planning (ERP), warehouse management, supply chain management (SCM).

\section{УДК 004.8}

\section{ИССЛЕДОВАНИЕ ИНФОРМАЦИОННЫХ СИСТЕМ УПРАВЛЕНИЯ ВЗАИМООТНОШЕНИЯМИ С ПОСТАВЩИКАМИ}

\section{Синха Бабу Раджа, Остроух А.B.}

\section{Аннотация}

$B$ статье анализируются различные подходы к построению информационных систем, автоматизирующих процессы учета, планирования и контроля. Показано, что система управления цепочками поставок создает единое информачионное пространство для всех компаний, участвующих в производстве продукта, его транспортировке, продаже и постпродажном обслуживании.

Ключевые слова: информационные системы, управление отномениями $c$ клиентами, планирование ресурсов предприятия, управление складом, управление цепями поставок.

Для эффективного ведения бизнеса сотрудники компаний вынуждены отслеживать и обрабатывать огромные объемы информации. Естественно, чем больше компания, чем больше клиентов, партнеров, тем острее становится вопрос о необходимости применения эффективных инструментов ведения бизнеса [1 - 10].

К таким инструментам относятся различные информационные системы, автоматизирующие процессы учета, планирования и контроля.

Применительно к транспортным и торговым компаниям, наиболее популярными в настоящее время информационными системами, являются: 
ERP - системы (англ. Enterprise Resource Planning, планирование ресурсов предприятия) - организационная стратегия интеграции производства и операций, управления трудовыми ресурсами, финансового менеджмента и управления активами, ориентированная на непрерывную балансировку и оптимизацию ресурсов предприятия посредством специализированного интегрированного пакета прикладного программного обеспечения, обеспечивающего общую модель данных и процессов для всех сфер деятельности. Обеспечивают автоматизацию планирования и контроль финансовых, человеческих и производственных ресурсов, формирование планов производства, управление запасами и закупками.

CRM-системы (Customer Relationship Management, управление отношениями с клиентами) - корпоративные информационные системы, незаменимый современный инструмент для ведения бизнеса. Дают возможность не просто автоматизировать взаимодействие с клиентами и процесс продаж, а выстроить их работу таким образом, чтобы получать максимальный результат.

Такие системы ориентированы на поддержку эффективного маркетинга, продаж и обслуживания клиентов. CRM-системы предоставляют необходимый функционал не только для сбора информации о клиенте - истории взаимоотношений с компанией, его предпочтениях и интересах, но, что более важно - содержат мощный инструментарий для анализа собранной информации и поддержки принятия управленческих решений $[3,4,10]$.

Задачи автоматизации управления складскими процессами решают системы класса WMS (Warehouse Management System).

Учет движения товаров на складе, оптимизация складского хранения, комплектация заказов, управление запасами - все это задачи, решаемые WMSсистемами.

Для транспортных компаний, и компаний, которые используют собственный автотранспорт для перемещения грузов, актуальным является использование систем управления транспортом - TMS системы (Transport Management System). Такие системы автоматизируют процессы планирования, оптимизации и контроля грузоперевозок, организацию консолидированных перевозок, планирование и формирование маршрутов, сбор статистики и анализ данных по транспортной логистике, мониторинг перевозки, и другие [4].

Как правило, функционал перечисленных систем реализован либо в виде соответствующих модулей основной EPR системы предприятия, либо в компании используются несколько специализированных систем, тесно интегрированных между собой.

Максимальный эффект от использования систем автоматизации процессов возможен только в том случае, если эти системы работают в едином информационном пространстве [1, 4].

Сейчас большинство компаний, внедривших у себя ERP-системы, сходятся во мнении, что автоматизированные системы планирования не решают всех задач предприятия. Для минимизации рисков, издержек, сохранения конкурентных 
преимуществ в условиях современной экономической и рыночной ситуации необходимо планировать и управлять не только внутренними ресурсами, но находиться в тесном взаимодействии со всеми участниками производственного процесса.

Действительно, по данным аналитической компании Gartner Group, наиболее развитыми блоками ЕRР-системы являются Финансы, Управление персоналом, Управление производством и Планирование цепей поставок (рисунок 1).

Блоки Управления поставщиками и выполнения цепей поставок так же присутствуют, но предоставляют минимальный функционал, необходимый для поддержания целостности данных.

Такая ситуация вполне объяснима, ведь ERP системы изначально создавались для планирования ресурсов предприятия, прежде всего финансовых и производственных. Управление поставками - непрофильная для ERP системы задача. Модули управления поставщиками и выполнения перевозок присутствуют в EPR системе, как правило для обеспечения минимальной целостности данных.

\section{Оценка функциональной полноты ERP}

(по данным Gartner Group)

$\begin{array}{lr}\text { Финансы } & 90 \% \\ \text { Управление персоналом } & \mathbf{8 0 \%} \\ \text { Управление производством } & \mathbf{7 5 \%} \\ \text { Планирование цепей поставок (SCP) } & \mathbf{7 0 \%} \\ & \\ \text { Управление поставщиками (SRM) } & \mathbf{6 0 \%} \\ \text { Выполнение поставок (SCE) } & \mathbf{4 0 \%}\end{array}$

\section{Рисунок 1 - Оценка функциональной полноты ERP}

Для наглядности обратимся к рисунку 2, на котором схематично отражены потребности предприятия и какую часть этих потребностей покрывают информационные системы. Синим овалом обозначены потребности организации, большую их часть решает ERP-система, какие-то задачи решает система CRM, SCM и так далее. Все эти системы интегрированы между собой и потому на рисунке пересекаются. 


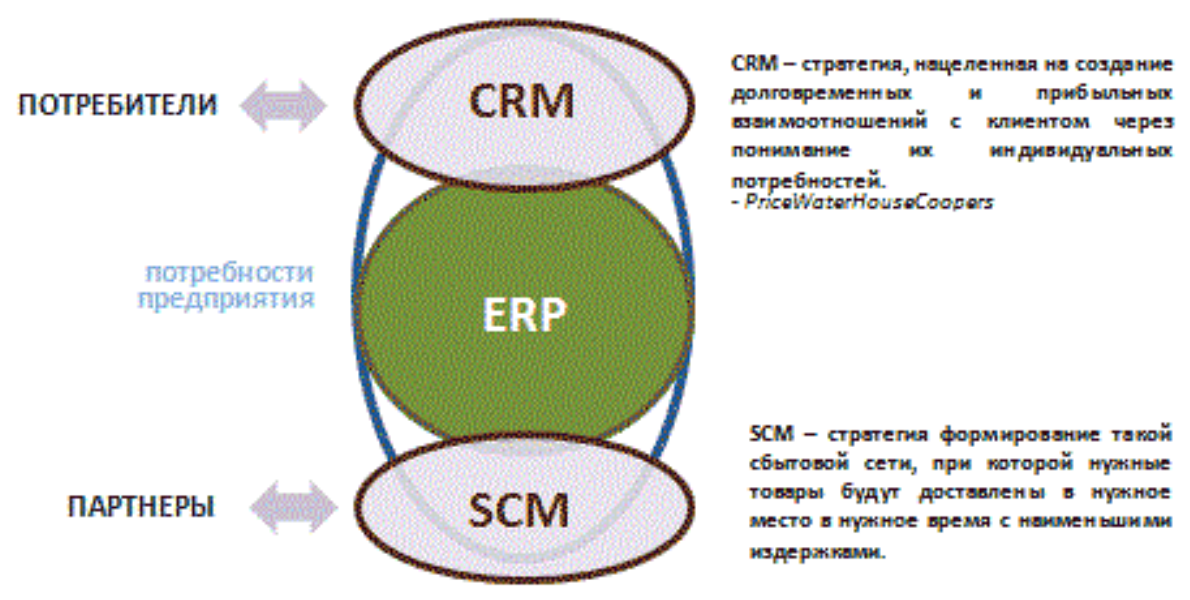

\section{Рисунок 2 - Функционал информационных систем не охватывает все потребности предприятия}

Но и на рисунке видно, и на практике выходит так, что функционал информационных систем не охватывает все потребности предприятия.

При опредлении тех функций, которые должны быть автоматизированы, надо помнить принцип 80/20, согласно которому 20\% усилий (затрат) дает $80 \%$ результата. Остальные $80 \%$ усилий - лишь $20 \%$ результата.

То есть необходимо понять тот рубеж, после которого затраты на дополнительное увеличение функционала системы не дают значимого эффекта.

При планировании корпоративной информационной системы руководство компании должно решить, какие из систем наиболее востребованы и, соответственно, должны быть наиболее развиты с функциональной точки зрения.

Международная консалтинговая компания PriceWaterhouseCoopers определяет CRM - как стратегию, нацеленную на создание долговременных и прибыльных взаимоотношений с клиентом через понимание их индивидуальных потребностей.

И, если CRM - философия работы с клиентами, SCM - философия работы с партнерами.

Концепция SCM подразумевает формирование такой сбытовой сети, при которой нужные товары будут доставлены в нужное место в нужное время с наименьшими издержками.

Достижение этой цели возможно только при эффективной интеграции поставщиков, производителей, дистрибьюторов и продавцов (рисунок 3 ). 


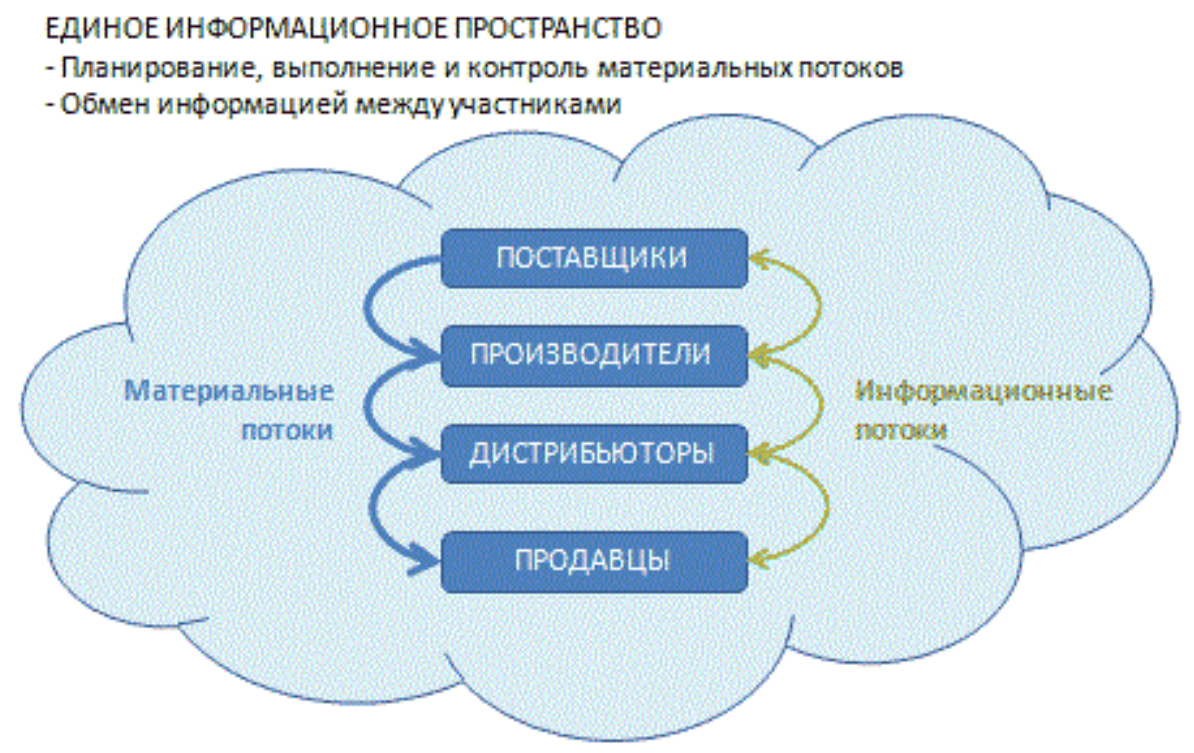

\section{Рисунок 3 - Единое информационное пространство по работе с клиентами и партнерами}

Система управления цепочками поставок представляет собой процесс организации планирования, исполнения и контроля потоков сырья, материалов, незавершенного производства, готовой продукции, а также обеспечения эффективного и быстрого сервиса за счет получения оперативной информации о перемещениях товара.

В условиях сложившейся экономической ситуации, ужесточения конкуренции и роста требований улучшения качества сервиса со стороны клиентов, чтобы сохранить конкурентные преимущества компаниям необходимо оптимизировать все процессы создания стоимости - от поставки сырья, до сервисного обслуживания конечного потребителя и утилизации продукции.

SCM-система обеспечивает планирование ресурсов и информационное сопровождение на протяжении всего жизненного цикла продукта - от заказа на разработку до послепродажного сервиса и утилизации, тогда как ERP система обеспечивает лишь планирование ресурсов, необходимых для разработки продукта (рисунок 4).

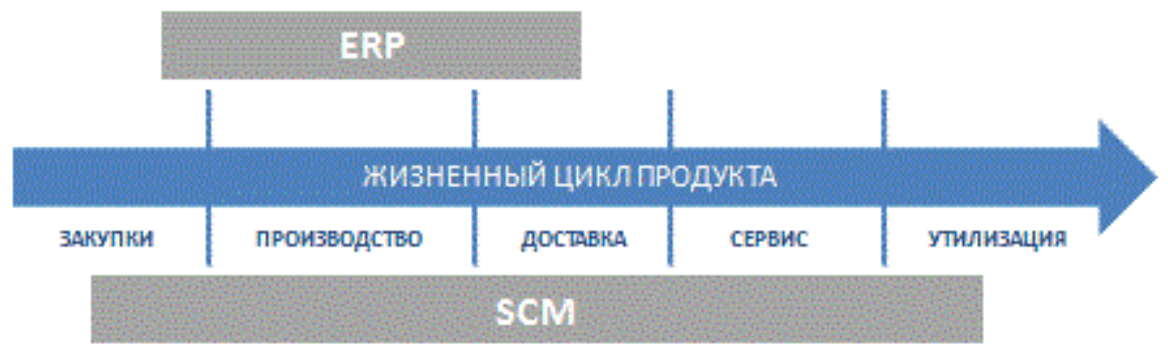

Рисунок 4 - Управление жизненным циклом продукта 
ERP система обеспечивает планирование и управление ресурсами при создании предопределенных видов продуктов, допуская незначительные изменения в составе продуктов.

SCM система позволяет планировать и управлять ресурсами при создании уникальных продуктов.

По данным аналитических компаний AMR Research, Forrester Research, успешное внедрение систем управления цепочками поставок дает компаниям преимущества (рисунок 5)

\section{Преимущества от внедрения SCM}

(по данным AMR Research, Forrester Research)

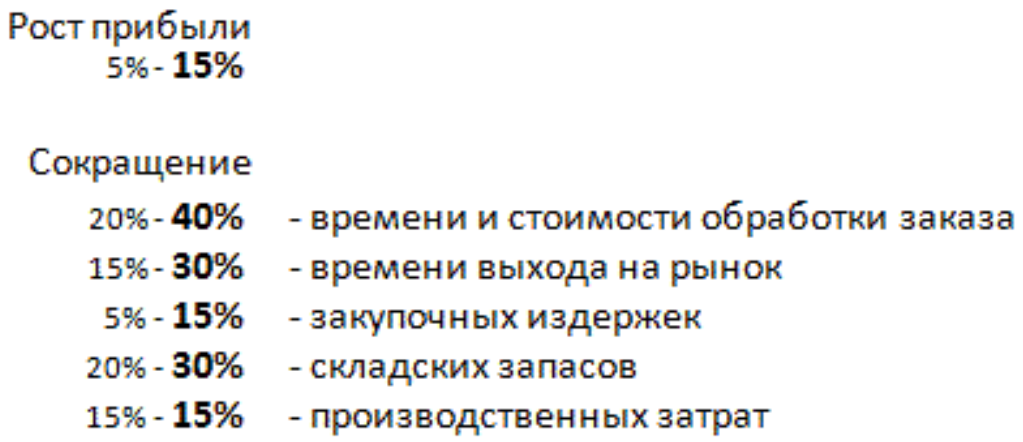

Рисунок 5 - Преимущества от внедрения SCM

Система управления цепочками поставок создает единое информационное пространство для всех компаний, участвующих в производстве продукта, его транспортировке, продаже и постпродажном обслуживании. Благодаря этому повышается уровень обслуживания и появляются дополнительные возможности для клиента, такие как, например, отслеживание состояния заказа в режиме реального времени.

\section{Список информационных источников}

[1] Кузнецов И.А. Особенности реализации автоматизированной информационноаналитической системы центра планирования перевозок строительных грузов / И.А. Кузнецов, А.В. Остроух // Вестник МАДИ(ГТУ). - 2008. - Вып. 1(12). - С. $92-$ 96.

[2] Куфтинова Н.Г. Процессно-ориентированный подход к автоматизации планирования и управления транспортировкой продукции предприятий промышленности / А.В. Остроух, Н.Г. Куфтинова // Вестник МАДИ - 2010. - Вып. 4(23). - С. 62-66.

[3] Николаев А.Б. Информационные технологии в менеджменте и транспортной логистике: учебное пособие / А.Б. Николаев, А.В. Остроух. - Saint-Louis, MO, 
USA: Publishing House Science and Innovation Center, 2013. - 254 c. - ISBN 978-0615-67110-9.

[4] Остроух, А.В. Информационные технологии в научной и производственной деятельности / [ред. А.В. Остроух] - М: ООО "Техполиграфцентр", 2011. - 240 с. ISBN 978-5-94385-056-1.

[5] Остроух А.В., Тянь Юань Современные методы и подходы к построению систем управления производственно-технологической деятельностью промышленных предприятий // Автоматизация и управление в технических системах. - 2013. - № 1(3); URL: auts.esrae.ru/3-53 (дата обращения: 31.10.2013).

[6] Приходько В.М., Солнцев А.А., Саная А.Г. Сетевая теоретико-игровая модель рациональных закупок в задаче формирования адаптивного механизма согласованных цен в схеме снабжения дилерской сети // Автоматизация и управление в технических системах. - 2013. - № 1(3); URL: auts.esrae.ru/3-70 (дата обращения: 31.10.2013).

[7] Саная А.Г. Модели аппроксимации показателей экономической эффективности инновационных проектов развития дилерских сетей // Автоматизация и управление в технических системах. - 2013. - № 2(4); URL: auts.esrae.ru/4-76 (дата обращения: 31.10 .2013$)$.

[8] Солнцев А.А. Модели нечеткого ситуационного анализа при описании вложенных процессов многоцелевой деятельности дилерской сети // Автоматизация и управление в технических системах. - 2013. - № 1(3); URL: auts.esrae.ru/3-71 (дата обращения: 31.10.2013).

[9] Суркова Н.Е., Угарова Ю.Н. Организация работы ИТ-подразделения в холдинговых структурах // Автоматизация и управление в технических системах. - 2013. - № 1(3); URL: auts.esrae.ru/3-59 (дата обращения: 31.10.2013).

[10] Ostroukh A.V., Kuftinova N.G. Automation of Planning and Management of the Transportation of Production for Food Processing Industry Enterprises. Automatic Control and Computer Sciences. 2012. Vol. 46. No. 1. pp. $41-48$. 